\title{
Effects of Operating Pressure on Energy-saving of Water Recycling Utilization with MVR system in Oil Extraction Fields
}

\author{
Li Liansheng*, Zhao Yuanyang, Wang Le, Xiao Jun, Yang Qichao, Liu Guangbin, Tang Bin
}

State Key Laboratory of Compressor Technology, Hefei General Machinery Research Institute, Hefei 230031, P. R. China

E-mail: lianshengli@126.com

Received 24 December 2014, Accepted 24 July 2015

\begin{abstract}
One of the most effective methods for the extraction of crude oil with high viscosity is injecting high temperature water vapor to the oil well. To save water consumption and achieve zero discharge, it is needed to separate and purify the water, which is mixed with oil, mud and other impurities. In this paper, the mechanical vapor recompression (MVR) system is analyzed and the parameters for analysis are based on a demonstration project on water recycling utilization in the Karamay crude oil field in northwest China. Two kinds of technological processes, high pressure and low pressure processes are proposed by the authors. The recovery work is utilized to decrease power consumption of the compression work and the energy from the high temperature purified water is used to drive an absorption refrigerator. The results show that $680 \mathrm{~kJ} / \mathrm{kg}$ of energy can be saved in the high pressure process compared to a low-pressure process. For low pressure process, the saving energy is only $420 \mathrm{~kJ} / \mathrm{kg}$, the material is easily corrosive, and additional 9.8t/h cooling water is needed. Compared the MVR system with TVR one, when the same pressure ratio and mass quantity of condensing water are obtained, the MVR system need use about $80 \mathrm{~kW}$ electrical power from compressor and the TVR system need use $3129.5 \mathrm{~kW}$ thermal energy from steam.
\end{abstract}

Keywords: Water recycling utilization; MVR; energy-saving analysis.

\section{Introduction}

Since the 1950s, the petroleum and natural gas have been becoming the main primary energy sources. And this dominance is expected to continue for several more decades [1]. Despite the growth in low-carbon sources of energy, the fossil fuels still remain dominant in the global energy market [2]. In the developing countries such as China, India and the Middle East, the petroleum and natural gas still take the key roles in the development of economy and society.

There are two problems during the extraction process of crude oil. One is that oil well becomes much deeper and the viscosity of crude oil is becoming much greater, so its extraction becomes very difficult. The other is that the crude oil extraction will consume much more resources such as energy and water, which results in serious environmental pollution [3].

To extract more crude oil or increase the efficiency of extraction, some methods and technologies are applied [4], [5]. For example, the artificial pressure lifts by pump, compressor or other lifting are used as conventional methods. To maintain pressure in the well, it is required to inject gas or liquid into well. To lower the viscosity of crude oil and increase its flow ability, the chemical or thermal techniques are used. Whatever method or technique is taken, the additional energy consumption will need. So, the most important thing is how to decrease additional consumption of energy.
The energy and exergy analyses of the oil and gas plant were conducted by some researchers. Oliveira and Van Hombeeck [6] conducted an exergy analysis of a Brazilian oil platform and found that the least exergy-efficient subsystem was the oil and gas separation, while the most exergy-consuming ones were the petroleum heating and the gas compression processes. Voldsund [7]-[8] carried out an exergy analysis of a Norwegian oil platform and showed that the greatest thermodynamic irreversibility was associated with processes where large changes in pressure took place. Nguyen [9]-[10] conducted a generic analysis of Norwegian oil and gas facilities as well as a mature field. They suggested that the most exergy-destruction generally exists in the production manifold and gas compression trains, which was particularly sensitive to the compressor and pump efficiencies, as well as to the petroleum composition. It was also shown that the separation work performed on the mature field is greater than in similar facilities because of higher propane and water fractions of the well-streams.

In the process of crude oil extraction, the environmental pollution is another big issue [11]. For the extraction of highviscosity crude oil, it is necessary to inject water vapor with high pressure and temperature into the well. But if the water is not in cyclic utilization, not only a lot of water resource is wasted, but also the environment around the well is polluted owing to the direct discharge of the water separated from the mixture, as shown in Figure 1. 


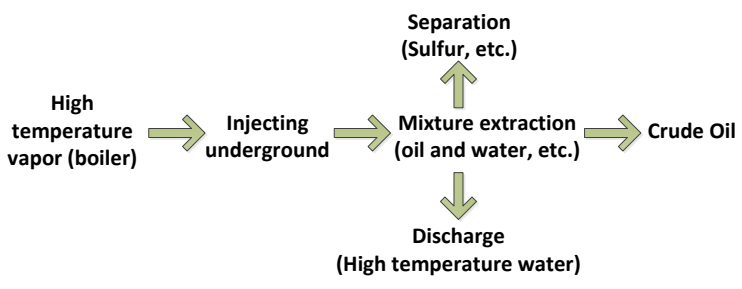

Figure 1. Traditional flow chart of oil extraction with vapor injecting.

To save energy and protect the environment, the water has to be utilized circularly in the extraction process of crude oil, and the schematic diagram is shown in Figure 2. Water from underground or other resources is pumped to boiler where the water is heated and becomes vapor with high temperature and pressure, and then vapor is injected into the oil well, in which oil with higher viscosity is diluted by the vapor [12]. Then the mixture of crude oil and vapor is extracted up to the ground and flows into the separator, where the mud, sulfur, $\mathrm{CO} 2$, water and so on are separated. The crude oil from the separator will be transported to the refinery.

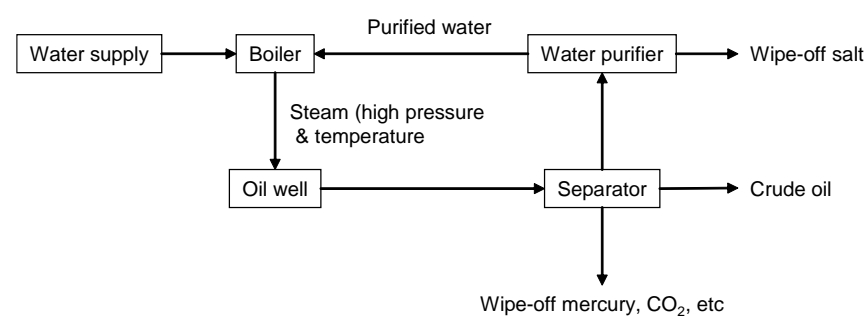

\section{Figure 2. Schematic diagram of water cyclic utilization.}

To get purified water for cyclic utilization, the water from separator must be desalted. The desalination process needs energy, and the quality of energy is related to the properties of salt water and the working condition of process system.

There are two basic methods to provide energy to evaporators, which are the thermal vapor recompression (TVR) and the mechanical vapor recompression (MVR) [6]. For an evaporator with MVR, the vapor leaving an evaporation stage is compressed to raise its saturation pressure and temperature. Then the compressed vapor can be used as heating steam in the same stage, and the main extra energy provided for evaporation is the mechanical work from compressor.

For TVR system, the vapor leaving the evaporator is compressed in the ejector by other steam (motive steam) with higher temperature and pressure. Hence the vapor can be reused as the heating steam. Here the input energy to the evaporator is from the motive steam.

The MVR systems became especially popular in the late 1970 's to early 1980 's. And it was used in the fields of chemical engineering, food processing, papermaking, and pharmacy processing, etc. [6-8]. In recent years, the new technologies of MVR were further investigated, and it was applied in some new fields such as materials, solar and so on [9-12].
In this paper, the energy saving analysis is done on water recycling utilization with MVR system in the field of crude oil extraction. The parameters for energy saving analysis are from a demonstration project in the Karamay crude oil field in northwest China. Two technical processes in MVR system are proposed, and the MVR and TVR are compared.

\section{Basic Principle of Water Recycling Utilization with MVR in Oil Extraction Field}

The Karamay crude oil field attached to China National Petroleum Corporation (CNPC), located at Northwest of China, is now extracting the crude oil with high viscosity by injecting the vapor at high temperature and pressure. The mixture flowing out from oil well is separated into crude oil, water, and other impurities, such as sulfur and $\mathrm{CO} 2$. There still exist grease dirty, salt and suspended solids in the water. The main focus of the research is on the water treatment. Hence, the main parameters of water are expressed in Table 1.

Table 1. Main Parameters of Water.

\begin{tabular}{ll}
\hline Parameter & Value \\
\hline Flow rate of water & $10 \mathrm{t} / \mathrm{h}$ \\
Pressure of water & $0.618 \mathrm{MPa}$ \\
Temperature of water & $160^{\circ} \mathrm{C}$ \\
Degree of dryness & Saturate water \\
Impurity in water & Grease dirty, salt, suspended solids \\
\hline
\end{tabular}

So far, in the process of extracting oil, the water separated from the mixture is directly discharged to the surroundings, which results in the environmental pollution and energy waste. To improve this situation, the water should be used circularly. Firstly, the grease dirty and suspended solids are divided from the water. Secondly, the salt is separated by evaporator with MVR. And finally, the purified water is pumped to the boiler. Thus the water cyclic utilization is realized.

Two basic technological processes, which are high pressure and low pressure processes, are proposed by the authors. The detailed explanation and analysis of these two processes are shown as below.

\subsection{Technological Process in Low Pressure}

The technological process of water cyclic utilization and its purification in low pressure process is shown in Figure 3.The mixture leaving the oil well is separated into crude oil, high temperature sewage with little grease, sludge, and other impurities.

The high temperature sewage of $10 \mathrm{t} / \mathrm{h}$ at the state of $160{ }^{\circ} \mathrm{C}$ and $0.6 \mathrm{MPa}$ flows into the degreaser firstly, where the grease and sludge are removed and at the outlet of degreaser water with salt is almost kept in the original flow rate, temperature and pressure. Then the water with salt enters the expander (process 0-1). The outputs of expander of $65 \%$ efficiency are $32 \mathrm{~kW}$. This power can be used to run the compressor in the MVR system. The state of water is $100^{\circ} \mathrm{C}, 0.1 \mathrm{MPa}$ and dryness of 0.11 at the outlet of expander (point 1'). Then the water goes into the vapor-liquid separator, where $1.1 \mathrm{t} / \mathrm{h}$ saturation vapor $\left(100{ }^{\circ} \mathrm{C}, 0.1 \mathrm{MPa}\right)$ flows into absorption refrigerator (point 2), and becomes the liquid water. And then the water is directly pumped to the boiler for recycling. 


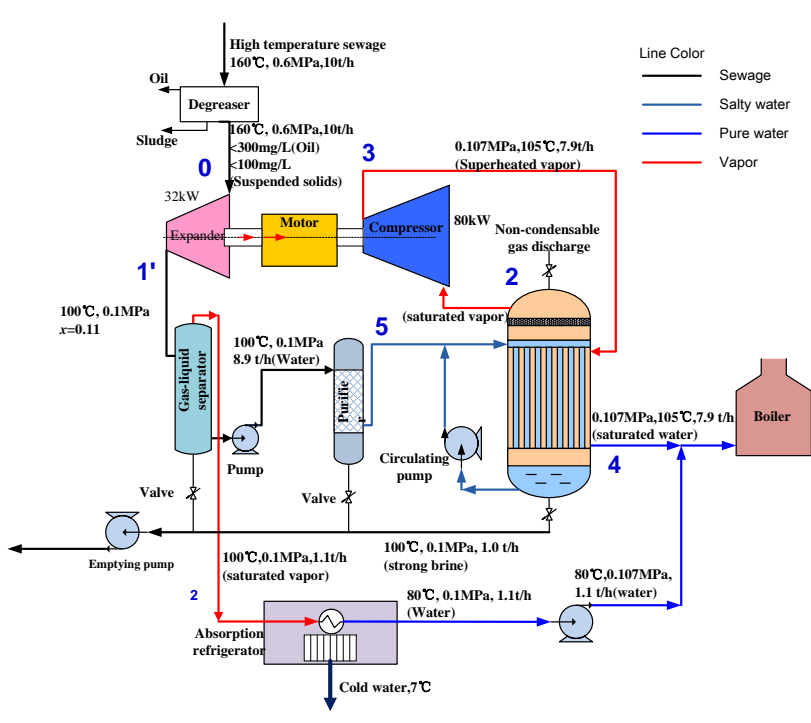

Figure 3. Water purification chart in low pressure process.

In the absorption refrigerator, the saturated vapor is condensed and releases the condensation heat for driving refrigerator. At the same time, the $7^{\circ} \mathrm{C}$ cold water can be gotten to be used for air conditioning of the working and living environment in extracting oil field.

The saturated water $\left(100^{\circ} \mathrm{C}, 0.1 \mathrm{MPa}\right)$ of $8.9 \mathrm{t} / \mathrm{h}$ flowed from vapor-liquid separator is pumped into the water purified system and evaporator for desalination. In the evaporator, the energy desired for desalination comes from vapor itself, i.e., the saturated vapor from the evaporator is compressed to a new state $\left(105^{\circ} \mathrm{C}, 0.107 \mathrm{MPa}\right)$ so that a temperature difference of $5{ }^{\circ} \mathrm{C}$ or above $5{ }^{\circ} \mathrm{C}$ is obtained, which can be used as the heat transfer power in evaporation process. The purified saturate water $\left(105^{\circ} \mathrm{C}, 0.107 \mathrm{MPa}\right)$ of about $7.9 \mathrm{t} / \mathrm{h}$ from evaporator flows into the boiler for reuse. The total amount of purified water reaches $9 \mathrm{t} / \mathrm{h}$.

For low pressure process, the salinity of water will increase when it flow out from the expander because there is some vapor produced during the expansion process. The $11 \%$ of the sewage is changed from water to saturation vapor. At this expansion process, all the salts are kept in the water. Hence the salinity of water which flow to the evaporator is higher than the original one of sewage.

The pressure-enthalpy $(p-h)$ diagram of MVR in the low pressure process is shown in Figure 4.

\subsection{Technological Process in High Pressure}

The pre-processing procedure in high pressure process is same as the one in the low pressure process. For the high pressure process (shown in Figure 5), the mixture is firstly separated into crude oil, high temperature sewage with small grease and sludge, and other impurities. Then the high temperature $10 \mathrm{t} / \mathrm{h}$ sewage at the state of $160^{\circ} \mathrm{C}$ and $0.618 \mathrm{MPa}$ flows into the degreaser, where grease and sludge are removed. At the outlet of degreaser, the water with salt almost keeps the original flow rate, temperature and pressure. Other impurities are further removed in the purifier, and the left water with salt $\left(160^{\circ} \mathrm{C}, 0.6 \mathrm{MPa}\right)$ goes directly into the evaporator for desalination, which means that water in the system will have higher pressure of more than $0.6 \mathrm{MPa}$.

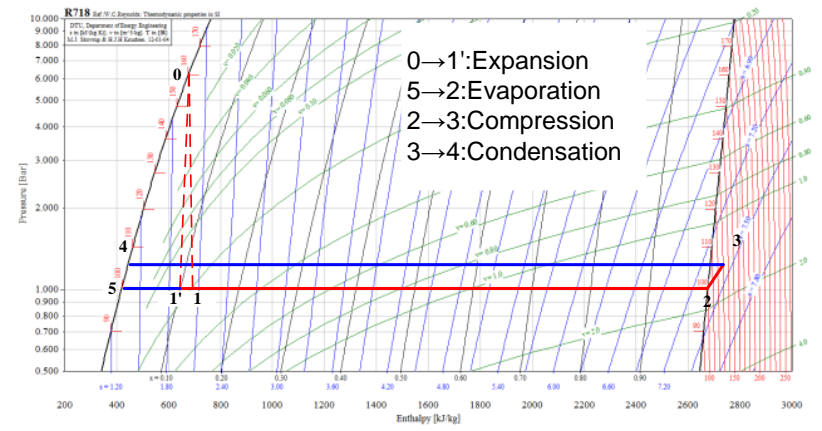

Figure 4. Pressure-enthalpy ( $p$-h) diagram for low pressure process.

The advantages of higher pressure flow include:

(1) The saturated temperature related to higher pressure is still higher.

(2) Owing to the high pressure, the power of pumping water to the boiler can be decreased.

The main disadvantage is that all the water with salt needs to be desalinated in the falling film evaporator.

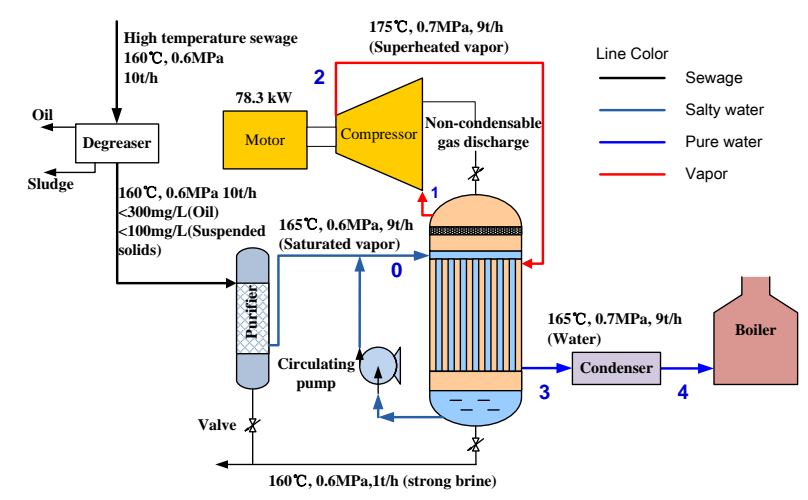

Figure 5. Water purification system in high pressure flow with MVR.

The pressure-enthalpy (p-H) diagram of water for MVR in the high pressure process is shown in Figure 6.

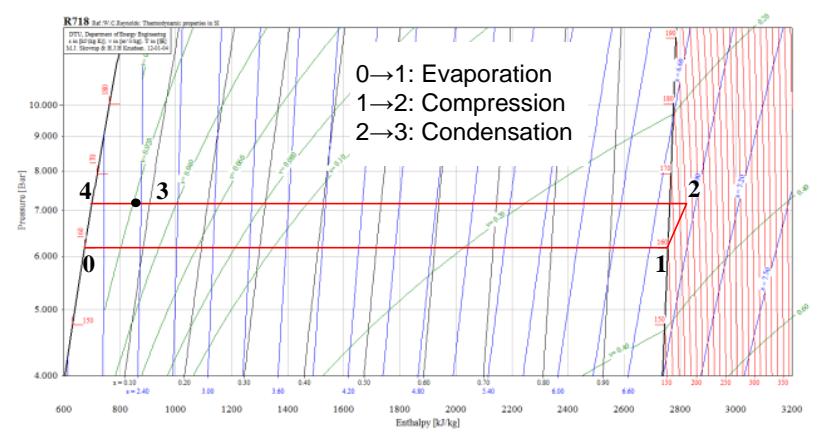

Figure 6. Pressure-enthalpy ( $p$-h) diagram for high pressure process.

\section{Flow Parameters Calculation and Efficiency Analysis 3.1. Low Pressure Process}

Thermodynamic parameters in low pressure process with MVR are shown in Table 2, in which the state points are expressed in Figure 4 and Figure 5. 
Table 2. Thermal Parameters of State in Low Pressure Process.

\begin{tabular}{lcccc}
\hline $\begin{array}{c}\text { State } \\
\text { point }\end{array}$ & $\begin{array}{c}\text { Temperature } \\
/{ }^{\circ} \mathrm{C}\end{array}$ & $\begin{array}{c}\text { Pressure } \\
/ \mathrm{MPa}\end{array}$ & $\begin{array}{c}\text { Enthalpy } \\
{\mathrm{J} . \mathrm{kg}^{-1}}^{-}\end{array}$ & Quality \\
\hline 0 & 160 & 0.617 & 675.7 & 0 \\
1 & 100 & 0.101 & 675.7 & 0.1137 \\
$1^{\prime}$ & 100 & 0.101 & 656.4 & 0.11 \\
2 & 100 & 0.101 & 2676.0 & 1 \\
3 & 120 & 0.120 & 2712.0 & 1 \\
4 & 105 & 0.120 & 440.7 & 0 \\
5 & 100 & 0.101 & 419.1 & 0 \\
\hline
\end{tabular}

\subsection{High Pressure Process}

The basic principle of MVR with falling film evaporation in high pressure process is shown in Figure 7. And the thermodynamic parameters of state points are shown in Table 3.

Table 3. Thermodynamic Parameters of the State Points in High Pressure Process.

\begin{tabular}{lccccc}
\hline State point & $\begin{array}{c}T \\
{ }^{\circ} \mathrm{C}\end{array}$ & $\begin{array}{c}P \\
\mathrm{MPa}\end{array}$ & $\begin{array}{c}\text { Density } \\
\mathrm{kg} \cdot \mathrm{m}^{-3}\end{array}$ & $\begin{array}{c}\mathrm{h} \\
\mathrm{kJ}_{\mathrm{kg}} \mathrm{kg}^{-1}\end{array}$ & Quality \\
\hline $\begin{array}{l}\text { 0(Saturated } \\
\text { water) }\end{array}$ & 160 & 0.618 & 907.45 & 675.47 & 0 \\
$\begin{array}{l}\text { 1(Saturated } \\
\text { vapor) }\end{array}$ & 160 & 0.618 & 3.26 & 2757.4 & 1 \\
$\begin{array}{l}\text { 2(Compression } \\
\text { outlet) }\end{array}$ & 175 & 0.701 & 3.57 & 2787.6 & \\
$\begin{array}{l}\text { 4(Condenser } \\
\text { outlet) }\end{array}$ & 165 & 0.701 & 449.94 & 705.7 & 0.004 \\
$\begin{array}{l}\text { 3(Saturated } \\
\text { water) }\end{array}$ & 165 & 0.701 & 902.51 & 697.2 & 0 \\
\hline
\end{tabular}

\subsection{TVR System}

The vapor ejector can also be used to lift the pressure of vapor. The evaporate system using vapor ejector is called TVR system. The main schematic diagram of TVR is shown in Figure 7.

In the MVR system and TVR system, the vapor is both reused by increasing the saturation pressure of the steam from the evaporator. Then the heat transfer can be achieved because there is temperature difference between the two sides of the evaporator. The main difference between MVR and TVR is that the energy is added to the system by an ejector using the high temperature steam in the TVR system. But the energy is added to the system by a compressor using mechanical power in the MVR system.

In the TVR system, the entrained steams are compressed in a steam ejector by motive steam, and the mixture (recompressed vapor) is used as the heating medium for the evaporator unit. Part of the vapors must be removed in a condenser to satisfy the material balance in the unit.

The motive steam is used the TVR system, which has higher temperature and pressure that that of entrained vapor. In the ejector, the entrained vapor is compressed by the motive steam. Hence the temperature of recompressed vapor is higher than that of entrained vapor and lower than that of motive steam. Thus the energy of motive steam is inputted into the entrained vapor. The recompressed vapor having high temperature can be used as the heating steam to heat the feed fluid.

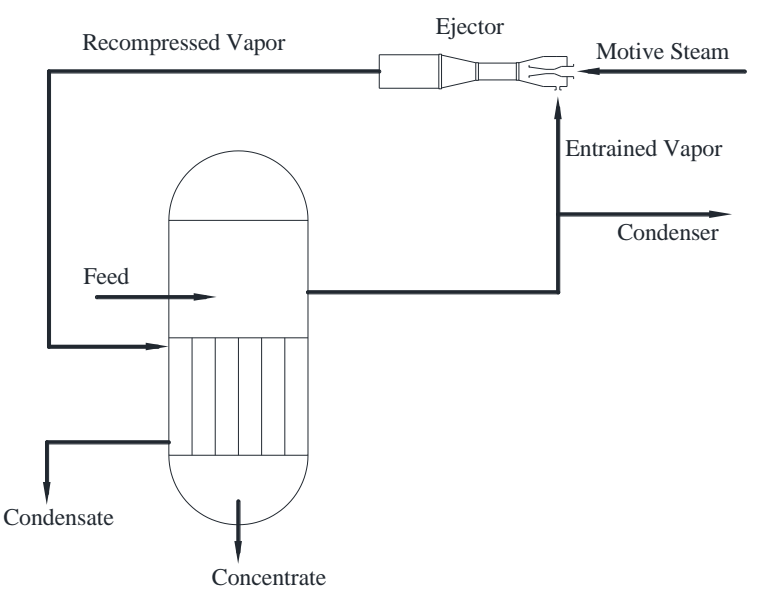

Figure 7. Schematic diagram of TVR.

Using the assumption of isentropic process, the heat quantity transmitted into the system can be calculated when the motive vapor is saturated steam of $150^{\circ} \mathrm{C}$ and the pressure of secondary steam is increased from $0.101 \mathrm{MPa}$ to $0.120 \mathrm{MPa}$.

$\mathrm{Q}_{\mathrm{o}}=\alpha m\left(h_{e}-h_{c}\right)=3129.5 \mathrm{~kW}$

$\alpha=0.25+1.6\left(\frac{\Delta \mathrm{i}_{2}}{\Delta \mathrm{i}_{1}}\right)+15.8\left(\frac{\Delta \mathrm{i}_{2}}{\Delta \mathrm{i}_{1}}\right)^{2}$

where the dissipation factor of work steam $\alpha$ is 0.613 [13], he is the enthalpy of $150{ }^{\circ} \mathrm{C}$ saturated steam, and hc is the enthalpy of $100^{\circ} \mathrm{C}$ saturated water.

\section{Results and Discussions}

\subsection{Comparison between High and Low Pressure Processes}

Table 4 shows the differences of two processes. It can be seen that the volume of equipment is different for different operating pressure. The volume would be small when using the high pressure process. The power consumption for different processes is not much different. But $9.8 \mathrm{t} / \mathrm{h}$ water is needed to cool the vapor for low pressure process. The expander is needed for low pressure process and the working condition of expander is very harsh. The reliability of expander is hard to guarantee.

Table 4. Comparison between High and Low Pressure Processes.

\begin{tabular}{lcc}
\hline Parameters & Low pressure flow & High pressure flow \\
\hline System pressure $/ \mathrm{MPa}$ & 0.1 & 0.6 \\
Working temperature $/{ }^{\circ} \mathrm{C}$ & $\sim 100$ & $\sim 160$ \\
Volume & Large & Small \\
Cooling water $/ \mathrm{t} . \mathrm{h}-1$ & 9.8 & 0 \\
Compression power $/ \mathrm{kW}$ & 80 & 78.3 \\
Energy saving $/ \mathrm{kJ} . \mathrm{kg}-1$ & 420 & 680 \\
\hline
\end{tabular}

Note: volume includes heat transfer, compressor, pipes, pump and valves. The steam volume flow rate of low pressure system is about 5 times of high pressure one. That means the compressor, steam pipe and heat exchanger for low pressure system is larger than the high pressure one.

\subsection{Energy Saving Comparison between TVR and MVR}

For the MVR system, the input power of the system is the mechanical power from the compressor when the power of pumps and other small power equipment are ignored. That 
means the input energy is about $80 \mathrm{~kW}$ electric powers for MVR system.

For the TVR system, the input power of the system is the thermal energy from the high temperature and pressures steam (motive steam). The quantity of thermal energy is $3129.5 \mathrm{~kW}$ to get the same quantity of condensing water.

Of course, it is difficult to compare the energy consumption for MVR and TVR systems. The grade of electric power and thermal energy is different. To get the same quality of electric power, about 3 times thermal energy is needed considering thermoelectric conversion efficiency.

The MVR system has higher efficiency on energy usage when comparing with the TVR system. But the reliability of the TVR system is higher than the MVR system because there is not rotating part in ejector.

The MVR system can also be used in the other fields of oil and gas industries. During the extract, refine and other process of petrochemical engineering, there are much salt water needed to be purified.

\section{Conclusions}

The MVR system with the falling film heat exchanger was analyzed and the parameters for analysis were based on a demonstration project of water recycling utilization in the Karamay crude oil field in China.

Two kinds of technological processes, high pressure and low pressure, were presented in detail and compared in this paper. The detailed flow charts for the high and low pressure processes were introduced too. Based on the thermodynamic analysis, the calculation and comparison of two processes were made. And the results show that the high pressure process can get $680 \mathrm{~kJ} / \mathrm{kg}$ of energy saving, as well compact volume, but its key parts will run at a high pressure. For low pressure process the energy saving is only $420 \mathrm{~kJ} / \mathrm{kg}$, the material is easily corrosive, and additional cooling water consumption of $9.8 \mathrm{t} / \mathrm{h}$ is desired. Compared the MVR system with TVR one, when the same pressure ratio and mass quantity of condensing water are obtained, the MVR system need use about $80 \mathrm{~kW}$ electrical power from compressor and the TVR system need use $3129.5 \mathrm{~kW}$ thermal energy from steam.

\section{Acknowledgements:}

The work was supported by the National Key Basic Research Program of China (2012CB026000), the Science and Technological Fund of Anhui Province for Outstanding Youth (1508085J05), and the science and technology plan of Anhui province (1501041128).

$\begin{array}{ll}\text { Nomenclature } \\ \mathrm{h} & \text { enthalpy } \\ \mathrm{m} & \text { mass flow rate } \\ \mathrm{P} & \text { power } \\ \mathrm{Q} & \text { heat quantity } \\ \alpha & \text { dissipation factor of work steam } \\ \eta & \text { efficiency }\end{array}$

\section{Subscripts}

c compressor

e expander

\section{References:}

[1] Yousif K. Kharaka, Nancy S. Dorsey, "Environmental issues of petroleum exploration and production: Introduction," Environmental Geosciences, doi:10.1306/eg.intro0605020205.

[2] International Energy Agency, World Energy outlook 2012 Available:http://www.worldenergyoutlook.org/publications/weo2012/ (accessed July 10, 2014).

[3] LI Yan-hong, XIE Qing-lin, "Technology of oil extraction wastewater treatment and application," J. of Guilin Institute of Technology, 23, 95-98, 2003. (In Chinese)

[4] Eduardo Camponogara, Agustinho Plucenio, Alex F. Teixeira, Sthener R.V. Campos, "An automation system for gas-lifted oil wells: Model identification, control, and optimization," J. of Petroleum Sci. and Eng., doi:10.1016/j.petrol.2009.11.003.

[5] Veselin Batalović, Dušan Danilović, Vesna Karovic Maricic, "Hydraulic lift systems with piston type pump," J. of Petroleum Sci. and Eng., doi:10.1016/j.petrol.2011.05.019.

[6] Oliveira Jr SD, Van Hombeeck M, "Exergy analysis of petroleum separation processes in offshore platforms," Energy Conversation and Management doi:10.1016/S0196-8904(96)00219-1.

[7] Voldsund M, Ertesvåg IS, He W, Kjelstrup S, "Exergy analysis of the oil and Gas processing a real production day on a North Sea oil platform," Energy, doi:10.1016/j.energy.2013.02.038

[8] Voldsund M, Nguyen T, Elmegaard B, Ertesvåg I, Røsjorde A, Jøssang K, Kjelstrup S., "Exergy destruction and losses on four North Sea offshore platforms: A comparative study of the oil and gas processing plants," Energy, doi:10.1016/j.energy.2014.02.080.

[9] Nguyen TV, Pierobon L, Elmegaard B, Haglind F, Breuhaus P, Voldsund M, "Exergetic assessment of energy systems on North Sea oil and gas platforms," Energy, doi:10.1016/j.energy.2013.03.011.

[10] Nguyen TV, Jacyno T, Breuhaus P, Voldsund M. Elmegaard B, "Thermodynamic analysis of an upstream petroleum plant operated on a mature field," Energy, doi:10.1016/j.energy.2014.02.040.

[11] Svalheim SM, "Environmental Regulations and Measures on the Norwegian Continental Shelf," in: Proceedings of the SPE International Conference on Health, Safety and Environment in Oil and Gas Exploration and Production, Kuala Lumpur, Malaysia, pp. 1-10, 2002.

[12] Mozaffar S, Nikookar M, Ehsani MR, Sahranavard L, Roayaie E, Mohammadi AH, "Numerical modeling of steam injection in heavy oil reservoirs," Fuel, doi:10.1016/j.fuel.2013.04.084.

[13] Wang Fuhua, Chemical engineering practical project design manual, Beijing: Xueyuan Press, 2002. (In Chinese) 